\title{
Value of Dermoscopy in a Population-Based Screening Sample by Dermatologists
}

\author{
Isabelle Hoorens $^{1}$, Katrien Vossaert ${ }^{1,2}$, Sven Lanssens ${ }^{2}$, Laurence Dierckxsens ${ }^{3}$, \\ Giuseppe Argenziano ${ }^{4}$, Lieve Brochez ${ }^{1}$
}

\author{
1 Department of Dermatology, University Hospital Ghent, Belgium \\ 2 Private Practice, Maldegem, Belgium \\ 3 Department of Dermatology, AZ Sint-Lucas, Ghent, Belgium \\ 4 Department of Dermatology, Second University of Naples, Italy
}

Key words: dermoscopy, screening, melanoma, basal cell carcinoma, squamous cell carcinoma

Citation: Hoorens I, Vossaert K, Lanssens S, Dierckxsens L, Argenziano G, Brochez L. Value of dermoscopy in a population-based screening sample by dermatologists. Dermatol Pract Concept. 2019;9(3):200-206. DOI: https://doi.org/10.5826/dpc.0903a05

Accepted: June 3, 2019; Published: July 31, 2019

Copyright: $\odot 2019$ Hoorens et al. This is an open-access article distributed under the terms of the Creative Commons Attribution License, which permits unrestricted use, distribution, and reproduction in any medium, provided the original author and source are credited.

Funding: None.

Competing interests: The authors have no conflicts of interest to disclose.

Authorship: All authors have contributed significantly to this publication.

Corresponding author: Isabelle Hoorens, MD, PhD, Department of Dermatology, Ghent University Hospital, Corneel Heymanslaan 10, 9000 Gent, Belgium. Email: isabelle.hoorens@uzgent.be

ABSTRACT Background: The use of dermoscopy improves the diagnosis of skin cancer significantly in trained dermatologists. However, to evaluate its cost-effectiveness in daily practice, not only sensitivity but also the excision rate is important.

Objective: We examined the diagnostic accuracy of cases from a true population-based sample scored by general dermatologists.

Methods: One hundred twenty-six dermatologists were randomly assigned to 145 digital cases of lesions detected at a skin cancer screening. This resulted in 4,655 case evaluations using a web application. Accuracy of diagnosis and treatment was correlated with the histological diagnosis or expert opinion.

Results: The larger portion $(89.7 \%)$ of the participating dermatologists reported using their dermatoscope daily. The odds of making a correct diagnosis of melanoma using dermoscopy was $5.38 \mathrm{com}-$ pared with naked-eye examination (NEE). Dermoscopy increased sensitivity for skin cancer diagnosis from $70.6 \%$ to $84.6 \%$, but this was associated with a small but significant decrease in specificity of $3.5 \%$. To detect 1 skin cancer, 5.23 lesions had to be biopsied/excised in this sample and this was not significantly improved by dermoscopic evaluation. Dermoscopy significantly increased the confidence about making a correct diagnosis, especially in seborrheic keratosis, Bowen disease, and melanoma.

Conclusions: Dermoscopy significantly improved diagnostic accuracy, the sensitivity of skin cancer detection, and the confidence in diagnosis especially for seborrheic keratosis, Bowen disease, and melanoma. However, this finding was not reflected in a significant reduction in the number needed to excise in this sample. 


\section{Introduction}

The skin cancer epidemic has an important impact on health care budget. Early detection and treatment is assumed to give better cure rates and subsequently a more cost-effective treatment. Dermoscopy is a well-established technique for diagnosis of melanoma and nonmelanoma skin cancer. Several meta-analyses have shown that dermoscopy, in the hands of experienced dermatologists, is superior to naked-eye examination (NEE) to detect melanoma [1-3]. Dermoscopy also significantly increases the diagnostic accuracy of nonmelanoma skin cancer diagnosis [4]. For basal cell carcinoma (BCC) the dermoscopic diagnostic accuracy is up to $95 \%-99 \%$ [5-7]. It is known that the diagnostic accuracy of dermoscopy depends significantly on training of the examiners [8]. In the hands of untrained practitioners, dermoscopy provides no better diagnostic accuracy for melanoma than NEE [1]. Most of the studies on the additional diagnostic value of dermoscopy have been performed in a well-selected set of lesions, in which melanomas and other malignant lesions are usually overrepresented. Since skin cancer prevalence in real-life setting is usually much lower, this can influence the number of false-positive diagnoses and their related cost in an important way (Bayes' theorem). For this reason we examined diagnostic accuracy and treatment allocation by NEE alone and additional dermoscopy among dermatologists in a population-based screening sample in Belgium.

\section{Methods}

\section{Study Design}

\section{Cases and Determination of Reference Diagnosis}

The cases were collected during a population-based lesiondirected skin cancer screening. Screenees could register for a free-of-charge skin cancer check-up if they had a lesion meeting 1 or more of the following criteria: ABCD rule, ugly duckling sign, a new lesion lasting more than 4 weeks, or red nonhealing lesions. All the index lesions presented by the screenees were checked and photographed both clinically and dermoscopically, respectively with an EOS 1200 D camera (Canon, Giessen, Germany) and the DermLite Photo System (3Gen, San Juan Capistrano, CA, USA). Following this lesion- directed screening, a total body check was offered to all participants for ethical reasons. We did not photograph any lesions during this second phase of the screening. In total 248 lesions were screened and 8 of them were histologically proven to be skin cancers $(3.2 \%)$. Further details on this screening initiative have been published elsewhere [9]. In total 145 of the 248 cases (58\%) were selected for a web application. Exclusion of cases was due to suboptimal quality of the photographs or a missing clini-
Table 1. Specific Diagnoses of Lesions in the $\mathbf{1 4 5}$ Cases

\begin{tabular}{|l|c|c|}
\hline & No. & \% \\
\hline Diagnosis & & \\
\hline Melanoma & 1 & 0.69 \\
\hline BCC & 4 & 2.76 \\
\hline SCC/Bowen & 1 & 0.69 \\
\hline Actinic keratosis & 3 & 2.07 \\
\hline Angioma & 5 & 3.45 \\
\hline Dermatofibroma & 4 & 2.76 \\
\hline Atypical nevus & 6 & 4.14 \\
\hline Blue nevus & 3 & 2.07 \\
\hline Congenital nevus & 6 & 4.14 \\
\hline Benign nevus & 53 & 36.55 \\
\hline Solar lentigo & 12 & 8.27 \\
\hline Seborrheic keratosis & 40 & 27.69 \\
\hline Other & 7 & 4.82 \\
\hline Total & 145 & 100 \\
\hline
\end{tabular}

SCC $=$ squamous cell carcinoma.

cal or dermoscopy image. This study was approved by the Flemish government and by the medical ethical committee of the University Hospital Ghent. All screenees provided written informed consent.

As a histological diagnosis was not available for most of the lesions, the following surrogate reference diagnosis was used in a hierarchical order: diagnosis of the pathologist in case of excision or biopsy of the lesion ( $\mathrm{n}=5 ; 3.4 \%$ ), concordant diagnosis by 2 blinded expert dermoscopists (K.V., L. B. $[n=100 ; 68.5 \%]$ ); in case of discordance in diagnosis by these 2 experts, a third independent and blinded expert dermoscopist (G.A.) was asked and the most concordant diagnosis was chosen $(\mathrm{n}=41 ; 28.1 \%)$. The gold standard diagnoses of all cases are listed in Table 1.

\section{Recruitment of Dermatologists}

A personal invitation to participate in this study was sent to all 384 Flemish certified dermatologists. One hundred twenty-six $(32.8 \%)$ dermatologists were included in the study. Participants were asked to register online and to evaluate 1 or more series of 25 cases each. Case series were presented randomly to each registered dermatologist. Upon registration, general information concerning their practice, previous training in dermoscopy, and the frequency of use of dermoscopy in routine practice was elicited.

\section{Case Evaluation}

Each online case mentioned brief clinical information (age, gender, and location of the lesion). First dermatologists were 
Table 2. Diagnostic Performance of Dermoscopy According to Level of Training of the Dermatologist

\begin{tabular}{|c|c|c|c|c|c|c|}
\hline & \multicolumn{3}{|c|}{ Clinical } & \multicolumn{3}{|c|}{ Dermoscopy } \\
\hline & Sens & Spec & 1 - Spec & Sens & Spec & 1 - Spec \\
\hline All & $\begin{array}{c}0.706 \\
(0.625-0.775)^{*}\end{array}$ & $\begin{array}{c}0.969 \\
(0.959-0.977) * *\end{array}$ & 0.031 & $\begin{array}{c}0.846 \\
(0.781-0.894) \\
\end{array}$ & $\begin{array}{c}0.935 \\
(0.915-0.950) * *\end{array}$ & 0.065 \\
\hline \multicolumn{7}{|l|}{ Training } \\
\hline$<5 \mathrm{hrs}$ & $\begin{array}{c}0.645 \\
(0.461-0.795)^{1}\end{array}$ & $\begin{array}{c}0.915 \\
(0.886-0.938)^{2}\end{array}$ & 0.085 & $\begin{array}{c}0.774 \\
(0.593-0.890)^{3}\end{array}$ & $\begin{array}{c}0.861 \\
(0.810-0.900)^{4}\end{array}$ & 0.139 \\
\hline $5-10 \mathrm{hrs}$ & $\begin{array}{c}0.702 \\
(0.588-0.796)^{1}\end{array}$ & $\begin{array}{c}0.921 \\
(0.903-0.935)^{2}\end{array}$ & 0.079 & $\begin{array}{c}0.829 \\
(0.726-0.899)^{3}\end{array}$ & $\begin{array}{c}0.885 \\
(0.854-0.910)^{4}\end{array}$ & 0.115 \\
\hline$>10 \mathrm{hrs}$ & $\begin{array}{c}0.704 \\
(0.593-0.795)^{1}\end{array}$ & $\begin{array}{c}0.940 \\
(0.927-0.951)^{2}\end{array}$ & 0.060 & $\begin{array}{c}0.852 \\
(0.755-0.915)^{3}\end{array}$ & $\begin{array}{c}0.887 \\
(0.861-0.909)^{4}\end{array}$ & 0.113 \\
\hline
\end{tabular}

Sensitivity and specificity, binomial generalized linear mixed models.

${ }^{\star} \mathrm{P}=0.002$ (odds ratio: 0.43 [95\% confidence interval: 0.26-0.73]).

${ }^{* *} \mathrm{P}<0.001$ (OR: 2.18 [95\% confidence interval: 1.84-2.58]).

$1,2,3,4 \mathrm{P}=\mathrm{NS}$.

shown the clinical picture and were asked to select a clinical diagnosis (multiple choice), to score the certainty of their diagnosis on a visual analogue scale from 0 to $100 \%$, and to choose the best treatment action (no treatment, biopsy, surgical excision, curettage, cryotherapy, and other); after registration of these answers they were shown the dermoscopy photograph and were asked to complete the same questions.

\section{Sample Size Calculation and Statistical Analysis}

A sample size of 1,630 case evaluations was required to achieve a power of $80 \%$ to detect a difference in specificity of $5 \%$ in the group of clinical evaluation compared with the group of additional dermoscopy evaluation with a significance level of $5 \%$. A specificity of $85.4 \%$ for the clinical diagnosis was expected and an interclass correlation of 0.814 was assumed (based on pilot data). Sample size calculation was adjusted for the clustered nature of the design by applying the method described by Killip et al [10]. Descriptive statistics were used to describe the cases and dermatologists participating. The related samples Wilcoxon signed rank test was used for continuous variables. Because of the clustered nature of the data, mixed logistic regression models were used to calculate sensitivity, specificity, and number needed to excise (NNE) and their relation to experience and training of the dermatologist. All statistical tests were 2-tailed and $\mathrm{P}$ values $<0.05$ were considered statistically significant. The analyses were conducted in SPSS version 21.0 (IBM, Armonk, NY, USA).

\section{Outcomes}

The primary outcome of this study was to evaluate the diagnostic accuracy of dermoscopy compared with NEE in a population-based setting. Furthermore, we wanted to evaluate whether dermoscopy can increase certainty of the correct diagnosis.

\section{Results}

\section{Participant Characteristics}

In total 126 dermatologists randomly evaluated 1 or more series of cases with a mean of 32.1 evaluations per case. This resulted in 4,655 case evaluations; $80.2 \%$ of the participants were female and $19.8 \%$ were male. The median age was 45 years (interquartile range [IQR]: 38-52). The majority of dermatologists worked in a private practice $(54.8 \%)$, $38.9 \%$ in a university center and $6.3 \%$ in a hospital setting. The reported median number of patients seen in routine practice was 100 per week (IQR: 70-130). Dermoscopy was used at least once a day in $89.7 \%$, once a week but not daily in $7.9 \%$, once a week up to once a month in $1.6 \%$, and not at all in $0.8 \%$. Thirty-seven $(29.4 \%)$ used a nonpolarized dermatosope. Training in dermoscopy varied among participants: only 3 dermatologists $(2.4 \%)$ had no training in dermoscopy, whereas $25(19.8 \%)$ had $1-5$ hours, $42(33.3 \%)$ had $5-10$ hours, and $44.4 \%$ had more than 10 hours of training.

\section{Diagnostic Accuracy and Certainty of Diagnosis}

Dermoscopy increased sensitivity for skin cancer diagnosis significantly from $70.6 \%$ to $84.6 \%$ (binomial generalized linear mixed model, $\mathrm{P}=0.002$; Table 2), associated with a small but significant decrease in specificity $(96.9 \%$ for NEE vs $93.5 \%$ for dermoscopy, binomial generalized linear mixed model, $\mathrm{P}<0.001$; Figure 1). The sensitivity for the diagnosis 

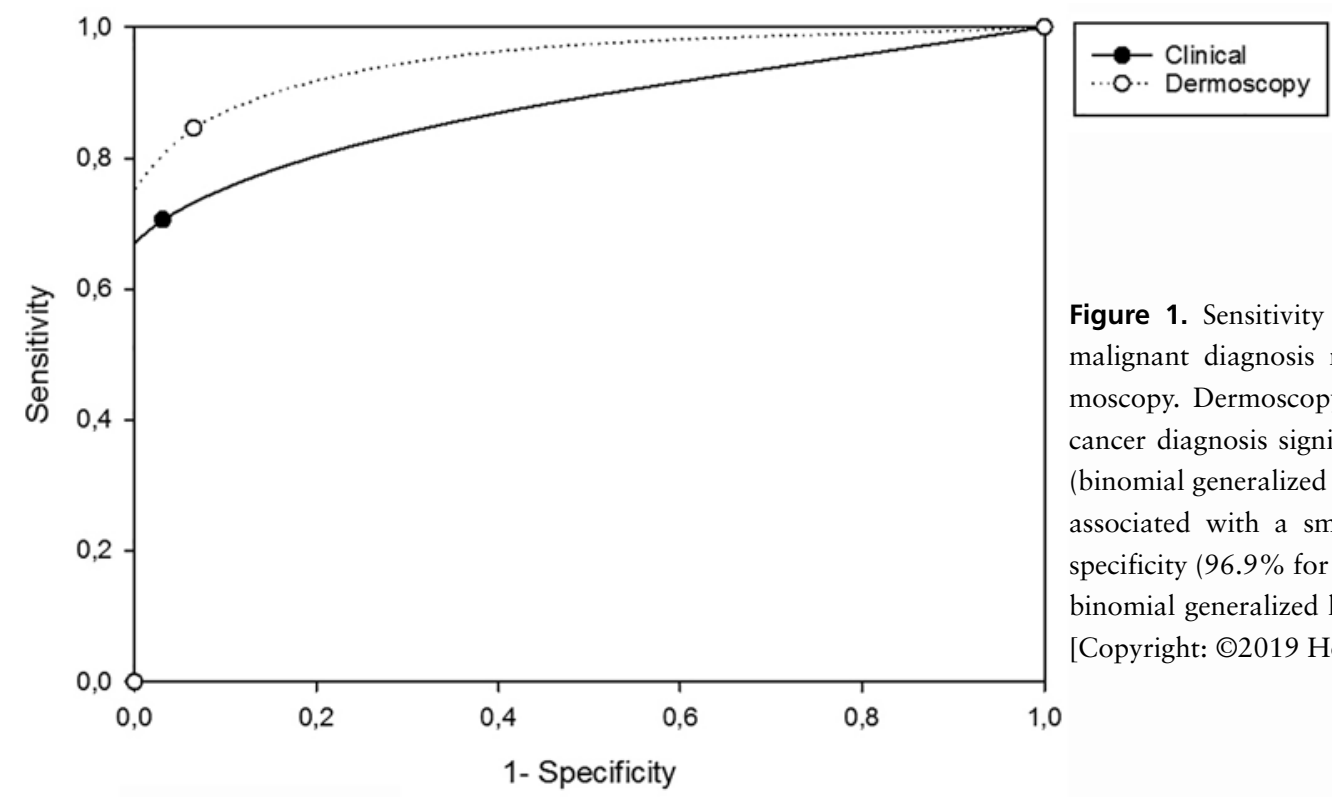

Figure 1. Sensitivity and 1 minus specificity for a malignant diagnosis made clinically and using dermoscopy. Dermoscopy increased sensitivity for skin cancer diagnosis significantly from $70.6 \%$ to $84.6 \%$ (binomial generalized linear mixed model, $\mathrm{P}=0.002$ ), associated with a small but significant decrease in specificity $(96.9 \%$ for NEE vs $93.5 \%$ for dermoscopy, binomial generalized linear mixed model, $\mathrm{P}<0.001$ ). [Copyright: @2019 Hoorens et al.]
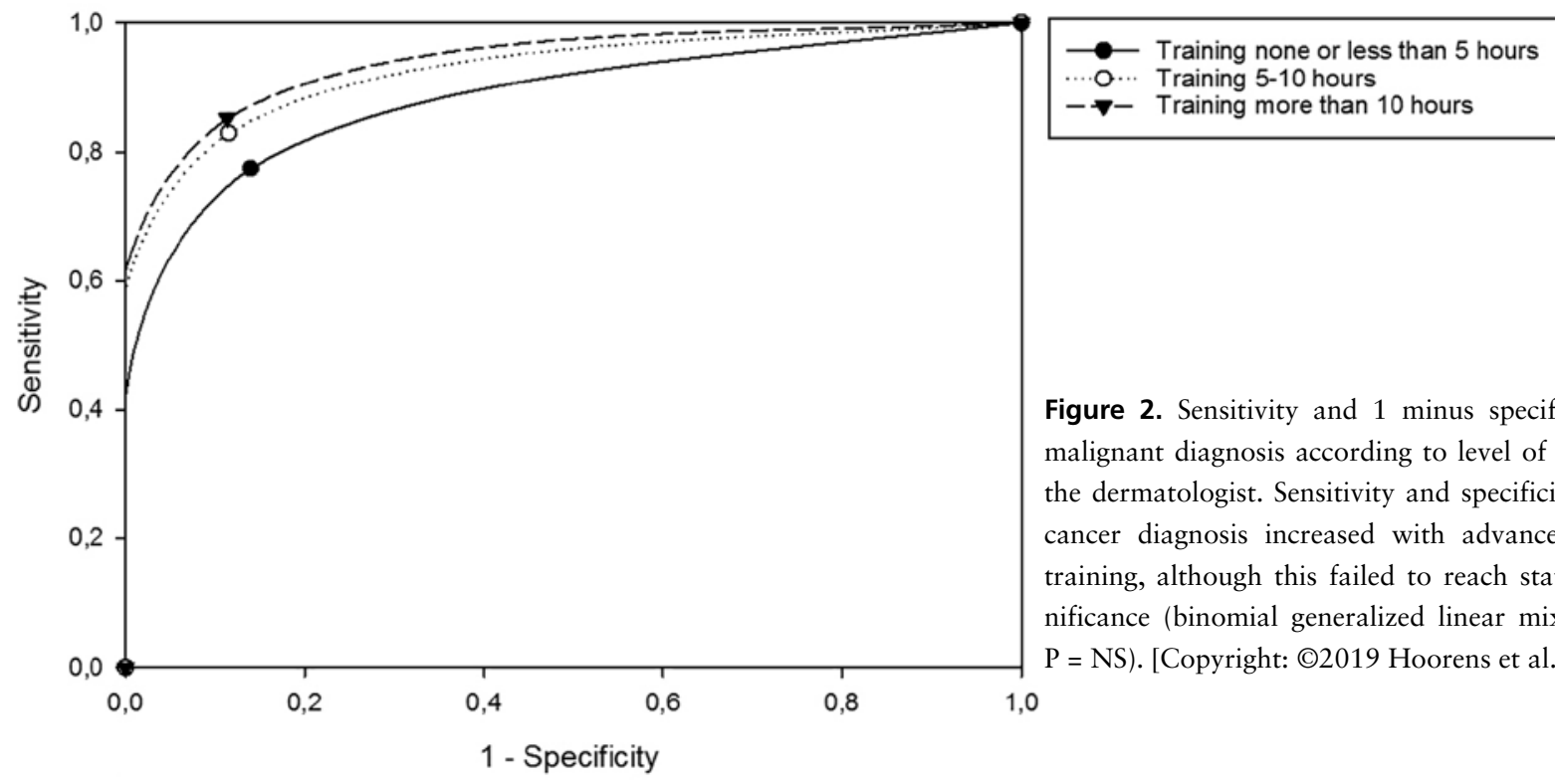

Figure 2. Sensitivity and 1 minus specificity for a malignant diagnosis according to level of training of the dermatologist. Sensitivity and specificity for skin cancer diagnosis increased with advanced level of training, although this failed to reach statistical significance (binomial generalized linear mixed model, $\mathrm{P}=\mathrm{NS})$. [Copyright: (2019 Hoorens et al.]

of melanoma with the use of dermoscopy increased even more from $76.0 \%$ to $94.0 \%$ (binomial generalized linear mixed model, $\mathrm{P}=0.028)$. The odds for making a correct diagnosis of melanoma using dermoscopy was 5.38 (95\% CI: 1.22-23.81) compared with NEE. Dermoscopy also increased sensitivity for diagnosis of BCC and squamous cell carcinoma/Bowen from $71.5 \%$ to $74.6 \%$, and $58.9 \%$ to $71.0 \%$, respectively, but this failed to reach statistical significance.

A trend to increasing sensitivity/specificity was observed with increasing training level (Figure 2). The confidence about a correct diagnosis significantly increased from a median of 70\% (IQR: $60-80$ ) using NEE to $83.7 \%$ (IQR: 70-90) with dermoscopy (related samples Wilcoxon signed rank test $(\mathrm{P}<$ $0.001)$ ). This increase was most pronounced for seborrheic keratosis, Bowen disease, and melanoma (Figure 3).

\section{Number Needed to Excise}

Dermoscopy resulted in 43 additional excisions for skin cancer and 252 extra excisions for benign lesions (on a total of 1,675 excisions or biopsies performed) compared with the clinical evaluation without dermoscopy. This resulted in a NNE of 4.77 for clinical evaluation alone and 5.23 when using dermoscopy (binomial generalized linear mixed model, $\mathrm{P}=$ not significant [NS]). The NNE did not seem to be influenced by training level (0-5 hours, NNE 5.15; 5-10 hours, NNE 4.89; and >10 hours, NNE 5.62; binomial generalized linear mixed model, $\mathrm{P}=\mathrm{NS}$; Table 3). Also for specific subcategories of lesions (melanocytic lesions and BCC) the NNE did not change significantly between clinical diagnosis and dermoscopy diagnosis (Table 3). 


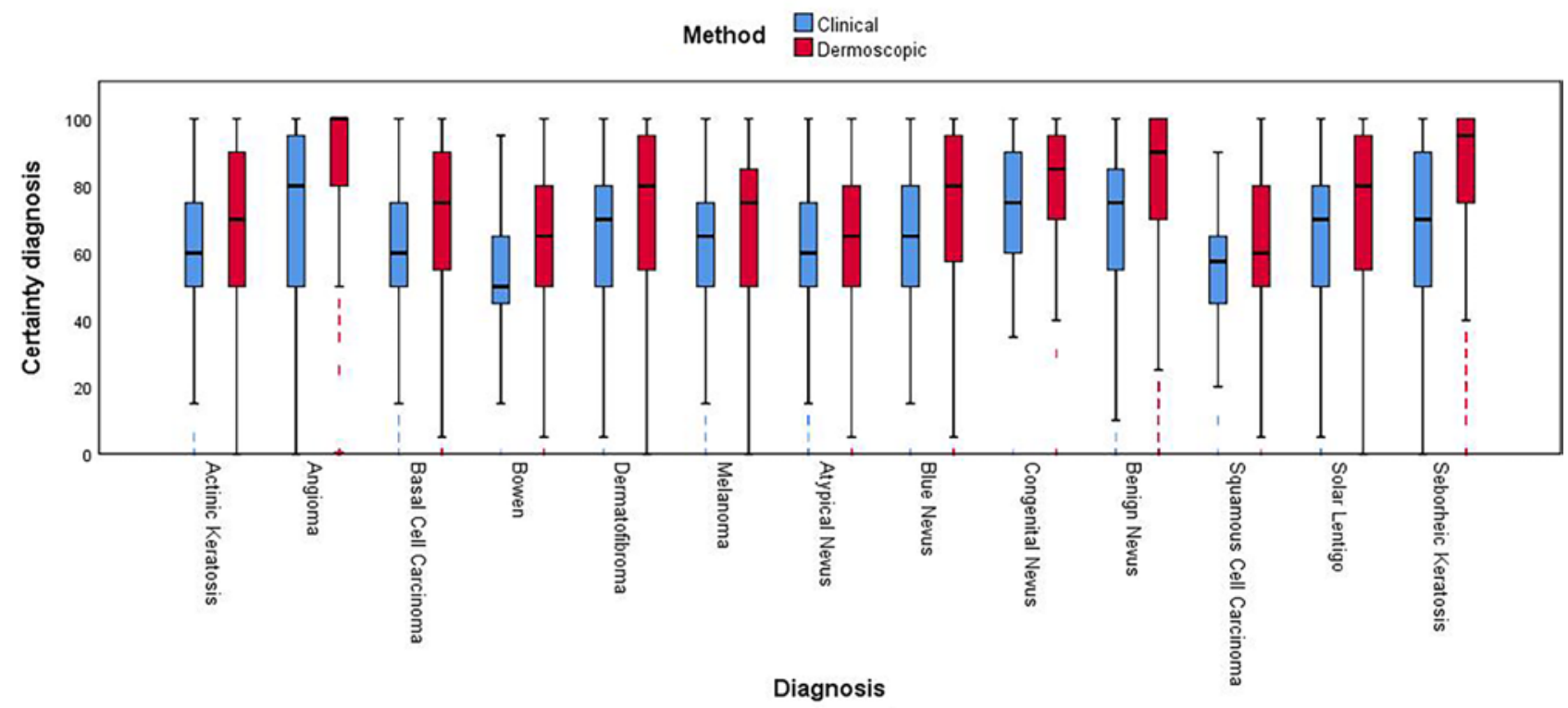

Figure 3. Median certainty of diagnosis clinically vs dermoscopy per diagnostic group. Certainty diagnosis median on visual analogue scale from 0 to $100 \%$. AK = actinic keratosis; VS = seborrheic keratosis. [Copyright: @2019 Hoorens et al.]

\section{Discussion}

In this study the additional value of dermoscopy over NEE diagnosis by 126 dermatologists was evaluated in a population-based series of 145 cases. In the past many similar studies have used very selected case series in which skin cancer was usually overrepresented. Although the intention is not to miss any skin cancer (100\% sensitivity), especially in melanoma, the importance of not overdiagnosing skin cancer (high specificity) may also be an important issue to avoid the individual (fear, unnecessary intervention) and societal (cost) disadvantages of false-positive diagnoses. In non-highrisk populations the specificity will have a higher impact on cost-effectiveness. In this study we therefore included a case series based on a population-based lesion-directed skin cancer screening program, in which skin cancer prevalence was only $6 / 145(4.1 \%)$. Nearly one third of all Flemish dermatologists evaluated at least 25 of the 145 cases. Cases were randomly presented to the participants, leading to a total of 4,655 case evaluations. In this way this study reflects the additional value of dermoscopy in the hands of general dermatologists in a population-based setting.

The results of this study demonstrate that dermoscopy is frequently used in Belgian dermatology practice: almost 90\% of participants use their dermatoscope daily. This is comparable with large studies performed in France and Australia (94.6\%-98\%) [11,12].

In accordance with other studies, we observed that dermoscopy significantly increases sensitivity for malignant lesions $[1-4,6]$. However, this results also in a small but significant decrease in specificity, thus increasing the number of false-positive diagnoses. In this study dermoscopy resulted in 43 additional excisions for skin cancer and 252 extra excisions for benign lesions over clinical diagnosis. The sensitivity/specificity tended to increase with increased level of training, confirming the results of previous studies $[1-4,6]$. Confidence about making a correct diagnosis was significantly higher using dermoscopy, especially in melanoma, seborrheic keratosis, and Bowen disease. However, this did not result in a reduction of unnecessary excisions as the NNE did not significantly differ between clinical diagnosis and dermoscopy nor did it seem to be influenced by training. Subanalyses with years of dermoscopy experience, daily use, in addition to level of training taken into account, also could not reveal a significant difference in the NNE. However, the NNE of the experts in the real-life setting on the screening (K.V., L.B.) was clearly lower than the NNE reached in the online case evaluation (ie, NNE 1.25 in reallife screening) [9].

The use of both clinical and dermoscopic photographs with the added information of gender, age, and lesion location to evaluate pigmented skin lesions remains somewhat artificial. In the absence of a total body inspection, individual lesions may be interpreted in a different way. An individual with multiple nevi, for instance, usually displays similar lesions (signature nevi); on the other hand there should be caution about lesions with a different pattern (ugly duckling sign). This was illustrated by 2 prominent nevi that were considered nonsuspicious by the 2 experts (K.V., L.B.) on the screening and were scored as potential melanoma in the online case series by at least 2 of 3 experts (G.A., K.V., L.B.). Digital follow-up of these lesions by means of new clinical and dermoscopy photographs about 20 months after screen- 
Table 3. NNE Dermoscopy vs Clinical Situation According to Level of Training

\begin{tabular}{|c|c|c|c|c|}
\hline All Lesions & $\begin{array}{l}\text { Level of } \\
\text { Training }\end{array}$ & $\begin{array}{c}\text { Excision/Biopsy } \\
\text { Malignant }\end{array}$ & $\begin{array}{c}\text { Excision/Biopsy } \\
\text { Benign }\end{array}$ & $\begin{array}{l}\text { Total Excisions } \\
\text { (NNE) }\end{array}$ \\
\hline \multicolumn{5}{|l|}{ Method } \\
\hline \multicolumn{5}{|l|}{ Clinical } \\
\hline & $<5 \mathrm{hrs}$ & 31 & 100 & $131(4.22)$ \\
\hline & $5-10 \mathrm{hrs}$ & 58 & 230 & $288(4.96)$ \\
\hline & $>10 \mathrm{hrs}$ & 61 & 235 & $296(4.85)$ \\
\hline Total & & 150 & 565 & $715(4.77) *$ \\
\hline \multicolumn{5}{|l|}{ Dermoscopy } \\
\hline & $<5 \mathrm{hrs}$ & 33 & 137 & $170(5.15)$ \\
\hline & $5-10 \mathrm{hrs}$ & 81 & 315 & $396(4.89)$ \\
\hline & $>10 \mathrm{hrs}$ & 79 & 365 & $444(5.62)$ \\
\hline Total & & 193 & 817 & $1010(5.23)^{*}$ \\
\hline $\begin{array}{l}\text { Melanocytic } \\
\text { Lesions }\end{array}$ & $\begin{array}{l}\text { Level of } \\
\text { Training }\end{array}$ & $\begin{array}{c}\text { Excision/Biopsy } \\
\text { Malignant }\end{array}$ & $\begin{array}{c}\text { Excision/Biopsy } \\
\text { Benign }\end{array}$ & $\begin{array}{l}\text { Total Excisions } \\
\text { (NNE) }\end{array}$ \\
\hline \multicolumn{5}{|l|}{ Method } \\
\hline \multicolumn{5}{|l|}{ Clinical } \\
\hline & $<5 \mathrm{hrs}$ & 14 & 51 & $65(4.57)$ \\
\hline & $5-10 \mathrm{hrs}$ & 22 & 126 & $148(6.73)$ \\
\hline & $>10 \mathrm{hrs}$ & 29 & 136 & $165(5.69)$ \\
\hline Total & & 65 & 313 & $378(5.81)^{*}$ \\
\hline \multicolumn{5}{|l|}{ Dermoscopy } \\
\hline & $<5 \mathrm{hrs}$ & 15 & 79 & $94(6.26)$ \\
\hline & 5-10 hrs & 36 & 195 & $231(6.41)$ \\
\hline & $>10 \mathrm{hrs}$ & 43 & 240 & $283(6.58)$ \\
\hline Total & & 94 & 514 & $608(6.46)^{*}$ \\
\hline $\mathrm{BCC}$ & $\begin{array}{l}\text { Level of } \\
\text { Training }\end{array}$ & $\begin{array}{c}\text { Excision/Biopsy } \\
\text { Malignant }\end{array}$ & $\begin{array}{c}\text { Excision/Biopsy } \\
\text { Benign }\end{array}$ & $\begin{array}{l}\text { Total Excisions } \\
\text { (NNE) }\end{array}$ \\
\hline \multicolumn{5}{|l|}{ Method } \\
\hline \multicolumn{5}{|l|}{ Clinical } \\
\hline & $<5 \mathrm{hrs}$ & 10 & 32 & $42(4.20)$ \\
\hline & $5-10 \mathrm{hrs}$ & 18 & 71 & $89(4.94)$ \\
\hline & $>10 \mathrm{hrs}$ & 17 & 54 & $71(4.18)$ \\
\hline Total & & 45 & 157 & $202(4.49) *$ \\
\hline \multicolumn{5}{|l|}{ Dermoscopy } \\
\hline & $<5 \mathrm{hrs}$ & 13 & 28 & $41(3.15)$ \\
\hline & 5-10 hours & 27 & 62 & $89(3.30)$ \\
\hline & $>10 \mathrm{hrs}$ & 20 & 47 & $67(3.35)$ \\
\hline Total & & 60 & 137 & $197(3.28)^{*}$ \\
\hline
\end{tabular}

NNE to find 1 confirmed skin cancer, melanoma, or BCC, binomial generalized linear mixed models. ${ }^{*} \mathrm{P}=\mathrm{NS}$.

ing showed no change, hence suggesting that these lesions have a benign behavior. This finding illustrates that some of the false-positive skin cancer diagnoses may have been due to the artificial conditions in which these lesions were evaluated.

Compared with previous studies, a NNE of 1 out of 6 was obtained in this study. Evaluation of the large SCREEN cam- paign in Germany in a partially nonspecialized setting not using dermoscopy resulted in 17 excisions of melanocytic lesions for the detection of 1 melanoma [13]. Our data are comparable with those of a large multicentric study examining excision rates over a period of 10 years in specialized clinical settings, with a NNE of 6.8 [14]. 
There was a trend toward increased sensitivity and specificity with increased training; however, training of $>10$ hours did not reach statistically significant superior results. In the recent NICE guidelines it is recognized that dermoscopy is unequivocally useful in the diagnosis of melanoma, but only in the hands of trained users [15]. The required amount of training, however, is a topic of debate. It has been shown that despite the frequent use of dermoscopy, training seems to be insufficient and that even among dermatologists who consider themselves experienced in dermoscopy, repeated training can increase diagnostic accuracy $[8,11]$. In addition, currently a lot of training courses in dermoscopy mainly focus on red flags (increased sensitivity for melanoma). However, when used in low-prevalence populations, it could be interesting to put more focus on green flags (recognition of harmless lesions), thereby reducing the number of false-positive diagnoses and hence unnecessary excisions.

\section{Conclusions}

The current study evaluated the additional value of dermoscopy in the hands of general dermatologists in a populationbased setting using a series of photos in a web application. These results demonstrate that dermoscopy clearly increases sensitivity for malignant lesions in a population-based setting at the expense of a small but significant decrease in specificity. Although dermoscopy significantly increased confidence about a diagnosis, especially in melanoma, seborrheic keratosis and Bowen disease, this did not result in a reduction of NNE. There was a trend toward higher sensitivity and specificity according to training level ( $<5$ hours, 5-10 hours, or $>10$ hours). We suggest that continuous training for dermoscopy is necessary and that training courses should also pay enough attention to the recognition of benign lesions to avoid unnecessary excisions and in that way benefit costeffectiveness ratios.

\section{References}

1. Kittler H, Pehamberger H, Wolff K, Binder M. Diagnostic accuracy of dermoscopy. Lancet Oncol. 2002;3(3):159-165.

2. Bafounta ML, Beauchet A, Aegerter P, et al. Is dermoscopy (epiluminescence microscopy) useful for the diagnosis of melanoma? Results of a meta-analysis using techniques adapted to the evalu- ation of diagnostic tests. Arch Dermatol. 2001;137(10):13431350 .

3. Vestergaard ME, Macaskill P, Holt PE, Menzies SW. Dermoscopy compared with naked eye examination for the diagnosis of primary melanoma: a meta-analysis of studies performed in a clinical setting. Br J Dermatol. 2008;159(3):669-676.

4. Pehamberger H, Binder M, Steiner A, et al. In vivo epiluminescence microscopy: improvement of early diagnosis of melanoma. J Invest Dermatol. 1993;100(3):356S-362S.

5. Altamura D, Menzies SW, Argenziano G, et al. Dermatoscopy of basal cell carcinoma: morphologic variability of global and local features and accuracy of diagnosis. J Am Acad Dermatol. 2010;62(1):67-75.

6. Menzies SW, Westerhoff K, Rabinovitz H, et al. Surface microscopy of pigmented basal cell carcinoma. Arch Dermatol. 2000;136(8):1012-1016.

7. Pan Y, Chamberlain AJ, Bailey M, et al. Dermatoscopy aids in the diagnosis of the solitary red scaly patch or plaque-features distinguishing superficial basal cell carcinoma, intraepidermal carcinoma, and psoriasis. J Am Acad Dermatol. 2008;59(2):268274.

8. Chevolet I, Hoorens I, Janssens A, et al. A short dermoscopy training increases diagnostic performance in both inexperienced and experienced dermatologists. Australas J Dermatol. 2015;56(1):52-55.

9. Hoorens I, Vossaert K, Pil L, et al. Total-body examination vs lesion-directed skin cancer screening. JAMA Dermatol. 2016;152(1):27-34.

10. Killip S, Mahfoud Z, Pearce K. What is an intracluster correlation coefficient? Crucial concepts for primary care researchers. Ann Fam Med. 2004;2(3):204-208.

11. Breton AL, Amini-Adle M, Duru G, Poulalhon N, Dalle S, Thomas L. Overview of the use of dermoscopy in academic and nonacademic hospital centres in France: a nationwide survey. J Eur Acad Dermatol Venereol. 2014;28(9):1207-1213.

12. Venugopal SS, Soyer HP, Menzies SW. Results of a nationwide dermoscopy survey investigating the prevalence, advantages and disadvantages of dermoscopy use among Australian dermatologists. Australas J Dermatol. 2011;52(1):14-18.

13. Waldmann A, Nolte S, Geller AC, et al. Frequency of excisions and yields of malignant skin tumors in a population-based screening intervention of 360,288 whole-body examinations. Arch Dermatol. 2012;148(8):903-910.

14. Argenziano G, Cerroni L, Zalaudek I, et al. Accuracy in melanoma detection: a 10-year multicenter survey. J Am Acad Dermatol. 2012;67(1):54-59.

15. National Institute for Health and Care Excellence. Melanoma-assessment and management of melanoma. (NG14) 2015. Availible at: http://www.nice.org.uk/guidance/ng14. Accessed March 15, 2019. 